\title{
Effect of intravenous aminophylline on the arterial oxygen saturation in chronic bronchitis
}

\author{
J . J D A L Y A N D P HOW AR D
}

\author{
From the Department of Medicine, The Royal Hospital, Sheffield, 1
}

A decrease in arterial oxygen saturation $\left(\mathrm{SaO}_{2}\right)$ has been observed to follow intravenous aminophylline administration in patients with chronic pulmonary disease (Halmagyi and Cotes, 1959). The decrease in $\mathrm{SaO}_{2}$ occurred 40 minutes or more after the injection in a group of patients who had shown an increase in maximum breathing capacity (M.B.C.) in response to the drug. The onset of symptomatic relief may occur within 15 minutes of the intravenous injection of aminophylline in patients with chronic bronchitis. In view of these observations the present study was designed to measure arterial blood gases and ventilation perfusion ratios at intervals between 2 and 50 minutes after intravenous injection of aminophylline in patients with chronic bronchitis.

\section{SUBJECTS}

Eighteen men aged between 44 and 73 years were studied. All had chronic bronchitis and emphysema and two had evidence of cor pulmonale. Results of ventilatory function tests are included in Table I. Maximum breathing capacity

T A B L E I

PHYSICAL CHARACTERISTICS, VENTILATORY MEASUREMENTS AND LUNG VOLUMES IN 18 PATIENTS WITH

\begin{tabular}{|c|c|c|c|c|c|}
\hline Name & Age & $\begin{array}{l}\text { Height } \\
\text { (cm.) }\end{array}$ & $\begin{array}{l}\text { Weight } \\
\text { (kg.) }\end{array}$ & $\begin{array}{l}\text { R.V. } \\
\text { (i.) }\end{array}$ & $\underset{(\text { I. 'min. })}{\text { M.B.C. }}$ \\
\hline $\begin{array}{l}\text { H.G. } \\
\text { G.W.A. } \\
\text { E.D. } \\
\text { H.P. } \\
\text { A.P. } \\
\text { G.D. } \\
\text { E.A. } \\
\text { J.P. } \\
\text { L.S. } \\
\text { S.P. } \\
\text { A.H. } \\
\text { F.R. } \\
\text { G.H. } \\
\text { W.C. } \\
\text { T.B. } \\
\text { H.N. } \\
\text { T.H. } \\
\text { F.H. }\end{array}$ & $\begin{array}{l}62 \\
61 \\
55 \\
44 \\
60 \\
60 \\
59 \\
54 \\
55 \\
54 \\
65 \\
63 \\
61 \\
59 \\
60 \\
68 \\
73 \\
58\end{array}$ & $\begin{array}{l}179 \\
163 \\
167 \\
183 \\
169 \\
171 \\
172 \\
175 \\
164 \\
165 \\
176 \\
159 \\
179 \\
168 \\
168 \\
169 \\
169 \\
160\end{array}$ & $\begin{array}{l}65 \\
59 \\
72 \\
73 \\
60 \\
71 \\
63 \\
64 \\
50 \\
75 \\
75 \\
59 \\
60 \\
61 \\
66 \\
67 \\
67 \\
57\end{array}$ & $\begin{array}{l}5 \cdot 13 \\
6 \cdot 78 \\
3 \cdot 4 \\
4.49 \\
5 \cdot 12 \\
4 \cdot 34 \\
4 \cdot 15 \\
2 \cdot 86 \\
3.90 \\
4 \cdot 35 \\
4.60 \\
4 \cdot 49 \\
5.8 \\
3 \cdot 63 \\
4 \cdot 87 \\
5 \cdot 3 \\
4.9 \\
2 \cdot 75\end{array}$ & $\begin{array}{l}31 \\
17 \\
44 \\
85 \\
13 \\
67 \\
45 \\
14 \\
36 \\
29 \\
72 \\
30 \\
20 \\
22 \\
10 \\
20 \\
18 \\
12\end{array}$ \\
\hline
\end{tabular}

R.V. = residual volume; F.E.V.0.78 $=$ forced expiratory volume in the first three-quarters of a second of expiration.
(F.E.V. $_{._{0} \cdot 75} \times 40$ ) was obtained using a Poulton $\stackrel{\odot}{+}$ spirometer (McKerrow, McDermott, and Gilson, 1960). Residual volume was estimated using + helium with a closed-circuit technique (Gilson and 음 Hugh-Jones, 1949). There was no clinical or electrocardiographic evidence of ischaemic heart disease and no subject had a blood pressure exceeding $160 / 100 \mathrm{~mm}$. $\mathrm{Hg}$.

\section{METHODS}

Patients rested for between two and four hours before the study. A Cournand needle was inserted into the brachial artery and a resting sample was $\triangle$ taken. In five men, $10 \mathrm{ml}$. of intravenous $0.9 \% \overrightarrow{\vec{B}}$ saline was given before sampling. Aminophylline, $\exists$ $0.25 \mathrm{~g}$., was injected intravenously during the next two minutes and two or three arterial samples were withdrawn at intervals during the following 50 minutes. In seven patients minute ventilation $\left(\dot{V}_{E}\right)$ was measured at the same time using a spiro- $\underset{x}{x}$ meter. In five patients ventilation-perfusion ratios $\dot{\sigma}$ were estimated before and after aminophylline 3 injection by a technique previously described 8 \% (West, Fowler, Hugh-Jones, and O'Donnell, 1957) using a mass spectrometer.

$\mathrm{SaO}_{2}$ was measured spectrophotometrically (Verel, Saynor, and Kesteven, 1960) and duplicate estimates were required to agree within $2 \%$. The $p \mathrm{H}$ was obtained using an E.I.L. $p \mathrm{H}$ meter and 0 glass electrode. Blood bicarbonate was measured $N$ by the method of Van Slyke and Neill (Van Slyke $\underset{\omega}{N}$ and Neill, 1924). Arterial $\mathrm{PCO}_{2}$ was obtained from $p \mathbf{H}$ and bicarbonate using a nomogram (Singer and Hastings, 1948). In a number of cases $\mathrm{PaCO}_{2} \stackrel{0}{\varnothing}$ was obtained by the method of Astrup (Astrup, $\stackrel{\mathscr{P}}{\rightarrow}$ Jørgensen, Siggaard Andersen, and Engel, 1960) or by Riley's bubble technique (Riley, Campbell, and Shepard, 1957). Inequality of ventilation and perfusion of the lung was expressed as a per- $\overrightarrow{\mathbb{D}}$ centage change of respiratory quotient (R.Q. scatter) between $300 \mathrm{ml}$. and $1,300 \mathrm{ml}$. of a prolonged expiration. 


\section{RESULTS}

Table II shows the results of blood gas estimations before and after aminophylline administration. Of the 18 patients four showed no significant change in $\mathrm{SaO}_{2}$. In six a decrease occurred ranging from $2 \%$ to $6.5 \%$ which persisted after 20 minutes. In the remaining eight, an increase between $2 \%$ and

T A B LE I I

SaO, AND PaCO, MEASUREMENTS BEFORE AND AFTER INTRAVENOUS INJECTION OF AMINOPHYLLINE

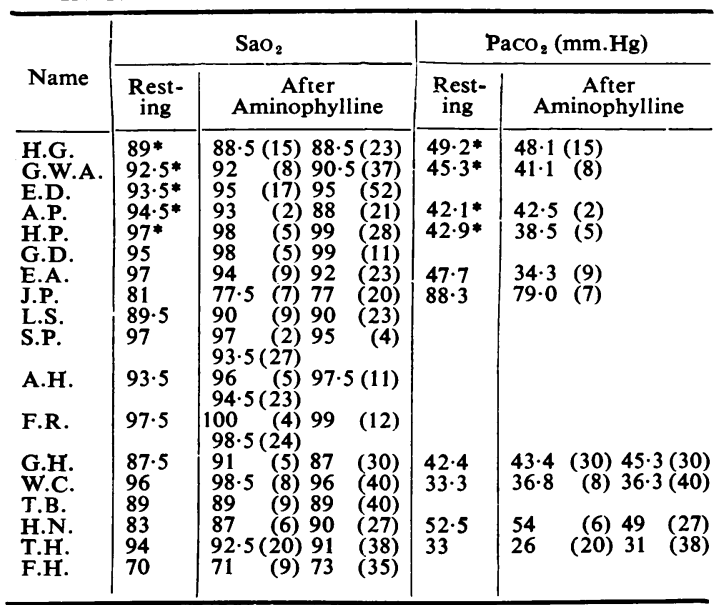

Figures in brackets refer to the time intervals in minutes following the injection of aminophylline.

* These patients were given intravenous saline prior to aminophylline.

$7 \%$ in $\mathrm{SaO}_{2}$ was observed. In six of these the response appeared within 10 minutes of the injection and in four $\mathrm{SaO}_{2}$ returned to the resting value but never below it by the twentieth minute. In summary, therefore, when an increase of $\mathrm{SaO}_{2}$ was noted, it tended to occur within 10 minutes but decreased to control values in half by the twentieth minute. By contrast, a decrease in $\mathrm{SaO}_{2}$ persisted longer (in one case up to 38 minutes), and in none of these patients did the values return to the resting level.

T AB L E III

PERCENTAGE CHANGE OF RESPIRATORY QUOTIENT BETWEEN 300 ML. AND 1,300 ML. (R.Q. SCATTER) OF SINGLE PROLONGED EXPIRATE BREATHS BEFORE AND AFTER AMINOPHYLLINE ADMINISTRATION COMPARED WITH THE CHANGE IN ARTERIAL OXYGEN SATURATION

\begin{tabular}{|c|c|c|c|c|c|}
\hline Name & At Rest & After & Aminoph & ylline & $\triangle \mathrm{SaO}_{2}$ \\
\hline $\begin{array}{l}\text { H.G. } \\
\text { E.A. } \\
\text { L.S. } \\
\text { A.H. } \\
\text { F.R. }\end{array}$ & $\begin{array}{rl}16 & 18 \\
16 & \\
14 & \\
7 & \\
24 & 20\end{array}$ & $\begin{aligned} 12 & (8) \\
17 & (5) \\
21 & (11) \\
4 & (4) \\
14 & (2)\end{aligned}$ & $\begin{array}{c}16(8) \\
25(15) \\
10(22) \\
4(11) \\
20(12)\end{array}$ & $\begin{array}{r}10(21) \\
22(33) \\
7(22) \\
10(20)\end{array}$ & $\begin{array}{l}\text { No change } \\
\downarrow(9) \downarrow(23) \\
\text { No change } \\
\uparrow(5) \uparrow(11) \\
\uparrow(4)\end{array}$ \\
\hline
\end{tabular}

Figures in brackets refer to the time in minutes after aminophylline administration that measurements were made.
In Table III, R.Q. scatter of prolonged expirate breaths before and after the injection of aminophylline is compared with the change of $\mathrm{SaO}_{2}$ in five patients. A decrease in $\mathrm{SaO}_{2}$ was accompanied by an increase in R.Q. scatter which is assumed to be equivalent to an increased ventilation perfusion inequality. An increase of $\mathrm{SaO}_{2}$ was accompanied by a decrease of R.Q. scatter.

\section{DISCUSSION}

An increase in heart rate, cardiac output, and minute ventilation, and a fall in pulmonary vascular resistance occurs in man after the intravenous injection of aminophylline (Fowell, Winslow, Sydenstricker, and Wheeler, 1949 ; James, Turner, and Merrill, 1948 ; Starr, Gamble, Margolies, Donal, Joseph, and Eagle, 1937 ; Storstein, Helle, and Rokseth, 1958 ; Zimmerman, 1951).

In a previous study (Halmagyi and Cotes, 1959) only one subject out of 13 showed an increase in $\mathrm{SaO}_{2}$ after intravenous injection of aminophylline. In the present study, an increase occurred in eight out of 18 patients. This difference is probably accounted for by the earlier sampling of blood in the present series of patients. A possible explanation of these findings would be an increase in ventilation to poorly ventilated areas. An increase of $\dot{V}_{E}$ (Table IV) or a decrease in $\mathrm{PaCO}_{2}$ occurred within 10 minutes in 11 out of 13 subjezts ; in six

T ABLE IV

MINUTE VENTILATION (V́E) BEFORE AND AFTER AMINOPHYLLINE ADMINISTRATION

\begin{tabular}{|c|c|c|c|c|}
\hline \multirow{2}{*}{ Name } & \multicolumn{4}{|c|}{$\dot{\mathrm{V}} \mathrm{E}(1 . / \mathrm{min})}$. \\
\hline & Resting & \multicolumn{3}{|c|}{ After Aminophylline } \\
\hline $\begin{array}{l}\text { F.R. } \\
\text { G.H. } \\
\text { W.C. } \\
\text { T.B. } \\
\text { H.N. } \\
\text { T.H. } \\
\text { F.H. }\end{array}$ & $\begin{array}{r}11 \cdot 4 \\
11 \cdot 3 \\
11 \cdot 9 \\
7 \cdot 6 \\
2.8 \\
6 \cdot 1 \\
13 \cdot 2\end{array}$ & $\begin{array}{r}14.5(4) \\
16.5(2) \\
13.1(3) \\
8.2(2) \\
11.4(2) \\
13.6(4) \\
14.9(3)\end{array}$ & $\begin{array}{r}13 \cdot 5(16) \\
8 \cdot 6(12) \\
13.7(14) \\
7.6(25) \\
7 \cdot 9(20) \\
10 \cdot 6(41) \\
13 \cdot 5(26)\end{array}$ & $\begin{array}{r}12.9(22) \\
9 \cdot 7(25) \\
11.7(31)\end{array}$ \\
\hline
\end{tabular}

Figures in brackets refer to the time in minutes after aminophylline administration that measurements were made.

out of $11 \mathrm{SaO}_{2}$ also increased. In the remaining two patients who showed an increase of $\mathrm{SaO}_{2}$ these measurements were not made.

The persistence of a decrease of $\mathrm{SaO}_{2}$ after 20 minutes in six patients was coincident with the return of $\dot{V}_{E}$ to near resting levels. An increase of blood flow to poorly ventilated areas or continuing perfusion of areas with a diminishing ventilation would be the most likely mechanisms to account for this finding. Halmagyi and Cotes (1959) observed a correlation between a decrease 
in $\mathrm{SaO}_{2}$ and an increase in M.B.C. following aminophylline injection. The M.B.C. (F.E.V. $\cdot_{0 \cdot 75}$ $\times 40$ ) was measured after aminophylline injection in eight patients, in four of whom a decrease of $\mathrm{SaO}_{2}$ had been previously observed. In only one of these four subjects did the M.B.C. increase by more than $10 \%$.

Ventilation perfusion ratios might be expected to alter after the administration of aminophylline, but the direction of change would be unpredictable and would depend on the size of the change in cardiac output and minute ventilation. In the few observations that were made reasonable agreement occurred between the changes in $\mathrm{SaO}_{2}$ and the changes in ventilation perfusion ratios (R.Q. scatter). This technique, however, gives the minimum value for ventilation perfusion inequality and tends therefore to underestimate the degree of abnormality present.

In summary, in those patients in whom there was no change in $\mathrm{SaO}_{2}$ it might be predicted that there is either no response to the drug or proportionate changes occur in ventilation and perfusion. In patients in whom an increase in $\mathrm{SaO}_{2}$ occurred this effect could have been due to an increase in $\dot{V}_{E}$ alone, while in those patients showing a decrease of $\mathrm{SaO}_{2}$, the most likely explanation is increased venous admixture. The results of the present investigation do not provide an explanation for the different types of response that occurred in this group of patients.

\section{SUMMARY}

Measurements of arterial oxygen saturation $\left(\mathrm{SaO}_{2}\right)$ were made before and after the intravenous injection of aminophylline in 18 men with chronic bronchitis but without evidence of ischaemic heart disease or hypertension. Estimations of ventilation perfusion inequality were made in five. $\stackrel{\overrightarrow{\bar{S}}}{\stackrel{9}{\circ}}$ A decrease of $\mathrm{SaO}_{2}$ occurred after the drug in six, an increase in $\mathrm{SaO}_{2}$ in eight, and there was no change in four. Increases in $\mathrm{SaO}_{2}$ tended to occur earlier and were less persistent than decreases of $\mathrm{SaO}_{2}$. Possible mechanisms are discussed.

We wish to thank Professor C. H. Stuart-Harris for advice and encouragement. We should also like to thank Mr. A. B. Kesteven, Mr. J. Bamforth, and Miss V. Home for invaluable technical help.

\section{REFERENCES}

Astrup, P., Jørgensen, K., Siggaard Andersen, O., and Engel, K. (1960). The acid-base metabolism. A new approach. Lancet, 1, 1035.

Fowell, D. M., Winslow, J. A., Sydenstricker, V. P., and Wheeler, N. C. (1949). Circulatory and diuretic effects of theophylline isopropanolamine. Arch. intern. Med., 83, 150.

Gilson, J. C., and Hugh-Jones, P. (1949). The measurement of the total lung volume and breathing capacity. Clin. Sci., 7, 185.

Halmagyi, D. F., and Cotes, J. E. (1959). Reduction in systemic blood oxygen as a result of procedures affecting the pulmonary circula tion in patients with chronic pulmonary disease. Ibid., 18, 475 .

James, D. F., Turner, H., and Merrill, A. J. (1948). Circulatory and C renal effects of aminophylline in congestive heart failure. Amer. J. Med., 5, 619 .

McKerrow, C. B., McDermott, M., and Gilson, J. C. (1960). A spirometer for measuring the forced expiratory volume with a simple calibrating device. Lancet, 1, 149.

Riley, R. L., Campbell, E. J. M., and Shepard, R. H. (1957). A bubble method for estimat

Singer, R. B., and Hastings, A. B. (1948). An improved clinical method for the estimation of disturbances of the acid-base balance of for the estimation of disturbances of the acid

Starr, I., Gamble, C. J., Margolies, A., Donal, J. S., Jr., Joseph, N., and Eagle, E. (1937). A clinical study of the action of $10 \mathrm{com}-$ monly used drugs on cardiac output, work and size; on respiration, on metabolic rate and on the electrocardiogram. J. clin. Invest. 16, 799.

Storstein, Ö., Helle, I., and Rokseth, R. (1958). The effect of theophylline ethylenediamine on the pulmonary circulation. Amer. Heart J., 55, 781

Van Slyke, D. D., and Neill, J. M. (1924). The determination of gases in blood and other solutions by vacuum extraction and manometric measurement. J. biol. Chem., 61, 523.

Verel, D., Saynor, R., and Kesteven, A. B. (1960). A spectrophotometric method of estimating blood oxygen using the Unicam S.P. 600.J. clin. Path., 13, 361.

West, J. B., Fowler, K. T., Hugh-Jones, P., and O'Donnell, T. V. (1957). Measurement of the ventilation-perfusion ratio inequality in the lung by the analysis of a single expirate. Clin. Sci., 16, 529. Zimmerman, H. A. (1951). A study of the pulmonary circulation in man. Dis. Chest, 20, 46. 